\title{
Service Time Management of Doctor's Consultation Using Parallel Service Time in Wesley Guild Hospital, Ilesa, Osun State, Nigeria
}

\author{
David O. Ikotun ${ }^{\mathrm{a}}$, Alaba T. Owoseni ${ }^{\mathrm{b}}$, Justus A. Ademuyiwa ${ }^{\mathrm{a}, \mathrm{b}, *}$ \\ ${ }^{a}$ Department of Mathematics and Statistics, Interlink Polytechnic, Ijebu Jesa, Nigeria \\ ${ }^{b}$ Department of Computer Science, Interlink Polytechnic, Ijebu Jesa and Department of Mathematics and \\ Statistics, Federal Polytechnic, Ile-Oluji, Nigeria
}

\begin{abstract}
How to manage patient's service time has been a burden in view of the condition of patients who have to wait for required service from doctors in many hospitals in developing countries. This paper deals with the management of service time of doctor's consultation using parallel service time. Though, the theoretical underlying distribution of service time is exponential, but this research showed service time to be nonexponential but, normal. This unusual distribution of service time was attributed to non-identical services required by patients from doctors in the considered sample space. Secondly, the mean service time from each service point as researched was found the same. This showed that no line could be preferred to other.
\end{abstract}

Index Terms: Service time, service point, exponential distribution, normal distribution, likelihood ratio test, central limit theorem.

(C) 2017 Published by MECS Publisher. Selection and/or peer review under responsibility of the Research Association of Modern Education and Computer Science

\section{Introduction}

A service time is the time a customer spends with the server in receiving service. The time it takes one particular server to complete a customers' service, is often used in making decision about resources needed to provide the services therefore, there is a need for service time management for effective and efficient decision making. Service time management may be in the hospital between a doctor and patients, in the banking halls between a cashier and customers and even at automated teller machine terminals.

The problem of very long service time cannot be underestimated, if service time is unduly long, the waiting time of later customers are very long. When customers are kept waiting in line for service, it may lead to break down of law and order. This happens at filling stations during the period of fuel scarcity for example,

\footnotetext{
* Corresponding author - Rogushina Julia.

E-mail address: ladamandraka2010@gmail.com
} 
Customers needing urgent attention that are kept waiting might develop various complications on the waiting line. Whenever expected inter arrival time is greater than mean service time, queue is developed and customers would consider the time spent on queue as wasting time.

The study of service time will provide expected utilization of server. Servers are usually paid and there is need to keep them optimized. A hospital cannot be of good service delivery if patients experience unduly long service time. People dislike long service time. Especially in hospitals and in order to improve level of service, hospital management board is usually interested in finding out the following:

- Is it worthwhile to invest effort on service time?

- Should priorities for certain customers be introduced?

- Is waiting area of customers adequate?

The application of "service time" may be of particular benefit in health sector with high size of customers. Service managers can make decision that increases the overall satisfaction of customers.

In this paper, it has been researched that the distribution of service time which is generally known to be exponential has been proved otherwise due to the studied population that is, in a hospital where services required by patients are not identical and so, we may experience a non-exponential distribution of service time. During the course of the study, a well-known medical teaching hospital was considered and the data used as contained in the appendix were analyzed scientifically.

Exponential distribution of service time is expected to be followed in communication industries where customers call in and out. This may not be so in a hospital setting, an institution providing medical and surgical treatment for sick or injured people. Customers coming with different ailments are not expected to spend the same time with the doctor on consultation.

\section{Related Works}

This section provides a theoretical framework for this work and they are logically grouped as follows:

\subsection{Arrival Process}

As presented in [1], a paper on Markovian arrivals in stochastic modeling and in [2], some simplified notation that carries as batch Markovian process were introduced. Also in [3], there was an analysis of gerberSlim discounted penalty function for risk processes with Markovian arrivals on insurance, mathematics and economics. Alfa A. S. and Neut, M. F. (1995) presented a paper on modeling vehicular traffic using discrete time Markovian process in transportation science [4] and in [5], stochastic process with application to biology was introduced.

Asmussen S. and Koole G (1993) marked points' process as limit of Markovian arrival stream [6]. [7] introduced queue theory and matrix analysis and in [8], the work introduced queuing system with arrival input disaster.

Lambert et al worked on queue with correlated service and inter-arrival times and application to optical buffers as contained in [9]. Meier-Hellstern K. S. and Neuts M. F. (1990) in [10] worked on a single-server queue with server vacations and a class of non-renewal arrival process.

\subsection{Service Time}

Halfin and Whilt (1981) developed server sizing heuristic for Erlang C model based on square root of staffing principle [11]. In [12], it was observed that the mean time was 53 minutes but customer preferred to spend maximum of 20 minutes. Also, as reviewed in [13], a positive correlation existed between arrival rate of 
customers and bank service rate. Green and Kolesar (1991) worked on point stationary approximation PSA in model arrival rate that vary slowly as compared to service level but, can be expressed as a function of time for example a sinusoidal varying arrival rate [14]. The theme that nuns through these papers is the challenge related to determine appropriate number of agents to staff given the tradeoff of operational cost and customer service. Beales 1995, Dantzig (1995) explicitly incorporate variability in parameter value known as stochastic program chance constraint program implement a confidence level of type constrains [15].

Ashley (2000) asserted that service system could promote service at faster rate than customer arrival rate; waiting line could still form if the arrival and service process were random [16].

Service time follows exponential distribution. In a situation where service received by customers are not the same, service may not follow exponential distribution.

\section{Methodology}

This section discusses the materials and methods used in the study. The methods include the statistical models used for analysis as discussed below:

\subsection{Maximum Likelihood Estimate of Mean $(\mu)$ and Variance $\left(\sigma^{2}\right)$}

$$
L=\left(\frac{1}{\sqrt{2 \pi \sigma^{2}}}\right)^{\mathrm{n}} e^{-\frac{1}{2 \sigma^{2}} \Sigma(\mathrm{ti}-\mu)^{2}}
$$

Log of likelihood:

$$
\log L=-n \log \sqrt{2 \pi}-\frac{n}{2} \log \sigma^{2}-\frac{1}{2 \sigma^{2}} \sum(\mathrm{ti}-\mu)^{2}
$$

$\frac{\delta \log L}{\delta \sigma^{2}}=\frac{-n}{2 \sigma^{2}}+\frac{1}{2\left(\sigma^{2}\right)^{2}} \sum(\mathrm{ti}-\mu)^{2}$

$\frac{\delta \log }{\delta \mu}=\frac{1}{\sigma^{2}} \Sigma(t i-\mu)^{2}$

Equate the equation to zero from (3):

$$
\begin{aligned}
& \frac{\delta \log L}{\delta \sigma^{2}}=\frac{1}{2\left(\sigma^{2}\right)^{2}} \sum(\mathrm{ti}-\mu)^{2}=0 \\
& \sigma^{2}=\frac{1}{n} \sum(t i-\mu)^{2}
\end{aligned}
$$

Since $\mu=\bar{t}$

$$
\sigma^{2}=\frac{1}{n} \Sigma(t i-\mu)=0
$$


From (3)

$\sum(t i-t)=0$

$\sum t i-\sum \mu=0$

$\sum t i=\sum \mu$

$\sum t i=n \mu$

$\mu=\frac{\sum \mathrm{ti}}{n}=t$

\subsection{Likelihood Ratio Test}

Let ti .......tn be random variable from $N\left(\mu, \sigma^{2}\right)$

$\mathrm{H}_{0}: \mu_{1}=\mu_{2}=\cdots \ldots \ldots=\mu_{\mathrm{g}}=\mu_{0}$

$\mathrm{H}_{\mathrm{i}}:$ Not $\mathrm{H}_{0}$

$f(t, \mu)=\left(2 \pi \sigma^{2}\right)^{\frac{-1}{2}} \exp ^{1 / 2(t-\mu)^{2}}$

$L(t, \mu)=\left(2 \pi \sigma^{2}\right)^{\frac{-n}{2}} \exp ^{1 / 2(t-\mu)^{2}}$

$\Delta(x)=\frac{L(\mu i / t)}{L(\mu o / t}>k x$

$\left(2 \pi \sigma^{2}\right)^{\frac{-1}{2}} \exp ^{1 / 2(t i-\mu)^{2}}$

$\left(2 \pi \sigma^{2}\right)^{\frac{-1}{2}} \exp ^{1 / 2(t-\mu)^{2}}=$

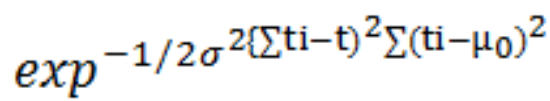

$\ln \Delta(x)=-{\frac{1}{2 \sigma^{2}}}^{\frac{1}{2}}[\Sigma \mathrm{ti}-\mathrm{t})^{2}-\Sigma(\mathrm{ti}-\mathrm{t})^{2}$

$2 \ln \Delta(x)=-\frac{1}{\sigma^{2}}\left[\sum \mathrm{ti}-\overline{\mathrm{t}}\right)^{2}-\sum\left(\mathrm{ti}-\mu_{0}\right)^{2}$ 


$$
\begin{aligned}
& \frac{1}{\sigma^{2}}\left[\sum \mathrm{ti}^{2}-2 \mu_{0} \sum \mathrm{ti}+\mathrm{n} \mu_{0}-\sum \mathrm{ti}^{2}+\right. \\
& \left.\sum \mathrm{ti}^{2}+2 \mathrm{t} \sum \mathrm{ti}-\bar{n} \bar{t}^{2}\right] \\
& \frac{1}{\sigma^{2}}\left[-2 n \mu_{0}^{2}+\mathrm{n} \mu_{0}^{2}+2 \mathrm{n} \bar{t}^{2}-\mathrm{n} \bar{t}^{2}\right. \\
& \frac{1}{\sigma^{2}}\left[n \mu_{0}+\mathrm{n} \bar{t}^{2}\right. \\
& \frac{n}{\sigma^{2}}\left[t^{2}+\mu_{0}^{2}\right. \text { Likelihood ratio test. } \\
& \frac{n}{\sigma^{2}}\left(t i-\mu_{0}\right)\left(t i-\mu_{0}\right) \\
& \left(\mu_{0} \sigma\right) t^{2} \rightarrow x_{1}^{2} \\
& \frac{n}{\sigma^{2}}\left(t^{-}+\mu_{0}\right)^{2}
\end{aligned}
$$

Squaring both sides:

$$
\begin{aligned}
& (2 \ln \Delta(x))^{2}=\left[\frac{\sqrt{n}}{\sigma^{2}}\left[\left(t-\mu_{0}\right)\right]^{2} \text { follow } \chi_{1}^{2}\right. \\
& (\mu, \sigma) t^{2} \rightarrow x_{1}^{2} \\
& \frac{n}{\sigma^{2}}\left(t-+\mu_{0}\right)^{2}
\end{aligned}
$$

\subsection{Data Presentation and Analysis}

Data is the information collected for the analysis of a given problem. The data collected involves 8 service point, seven other people were employed for data collection. The number of customers served in 120 minutes each day by the doctor were observed and recorded in minutes.

\subsubsection{Data Presentation}

The figures below show the histograms of service time against the total number of patients on daily basis per doctor (server) using "R" statistical package for the representation. 


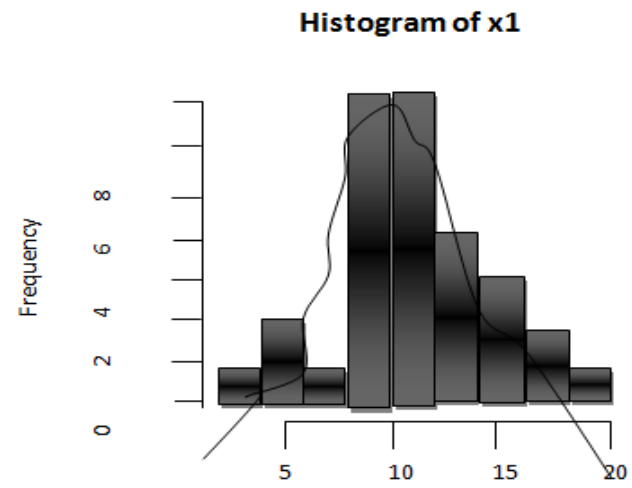

Fig.1. Histogram for Server 1 (Doctor)

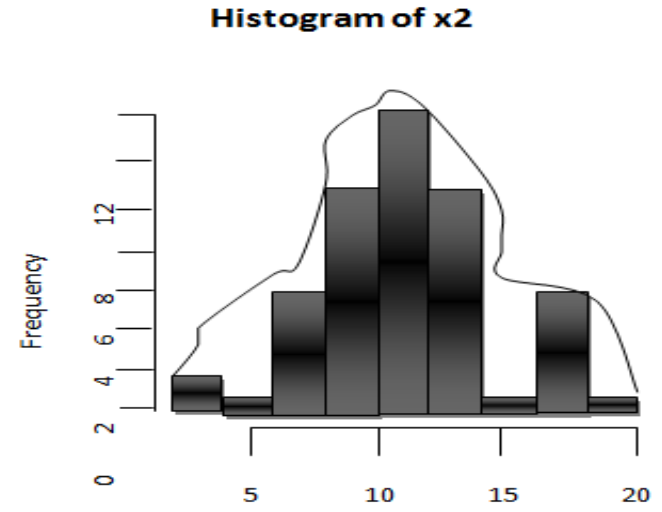

Fig.2. Histogram for Server 2(Doctor)

\section{Histogram of $\times 3$}

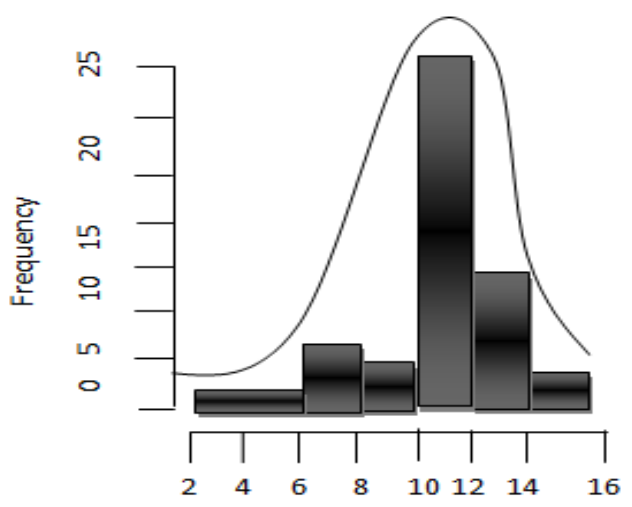

Fig.3. Histogram for Server 3(Doctor) 


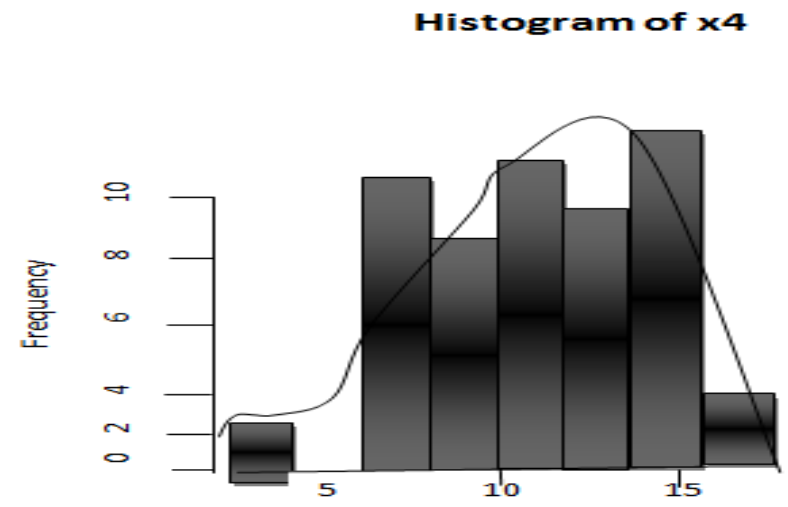

Fig.4. Histogram for Server 4(Doctor)

Histogram Of xs

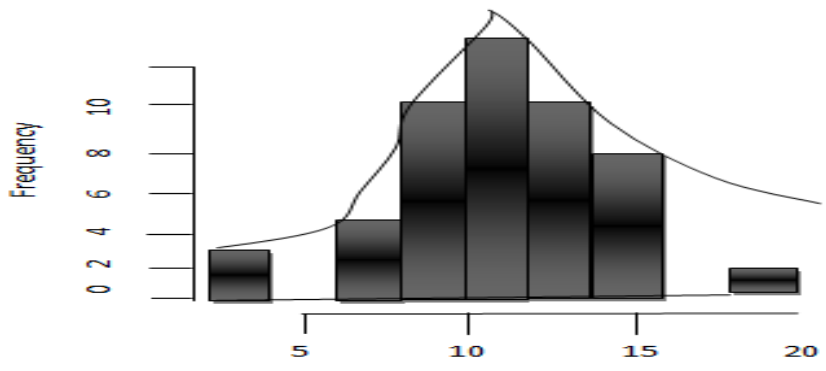

Fig.5. Histogram for Server 5(Doctor)

Histogram of $\times 6$

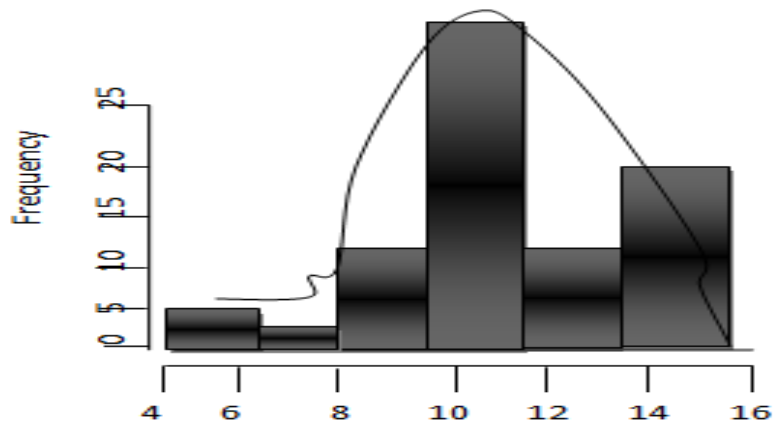

Fig.6. Histogram for Server 6(Doctor) 


\section{Histogram of $\mathrm{X} 7$}

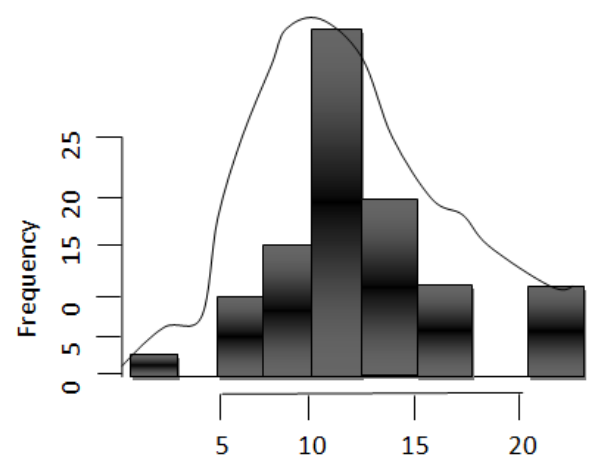

Fig.7. Histogram for Server 7(Doctor)

\section{Histogram of $x 8$}

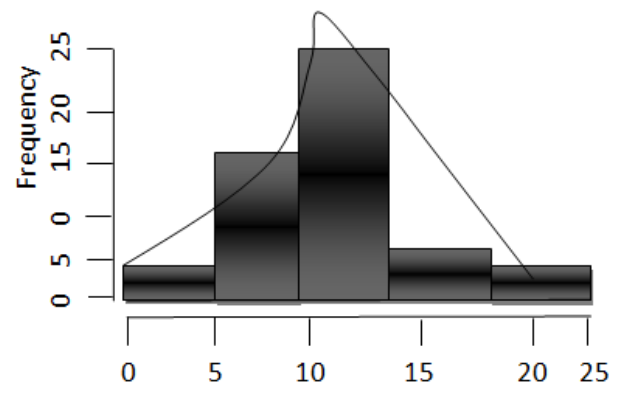

Fig.8. Histogram for Server 8(Doctor)

\subsubsection{Kolmogorov-Smimov Tests' Result}

Server 1:

\section{Fig 1: Histogram for server 1}

$>$ Ks. Test (s6, pexp, mean (s1))

One-simple Kolmogorov-Smirnov test

data: s6

$$
D=1, p-\text { value }<2.2 e-16
$$

Alternative hypothesis: two-sided

Server 2: 
Fig 2: Histogram for server 2

$>$ Ks. Test (s6, pexp, mean (s2))

One-simple Kolmogorov-Smirnov test

data: s6

$$
D=1, p-\text { value }<2.2 e-16
$$

Alternative hypothesis: two-sided

Server 3

Fig 3: Histogram for server 3

$$
\text { Ks.Test }(s 6, \text { pexp, mean (s3)) }
$$

One-simple Kolmogorov-Smirnov test

data: s6

$$
D=1, p-\text { value }<2.2 e-16
$$

Alternative hypothesis: two-sided

Server 4:

Fig 4: Histogram for server 4

$>$ Ks. Test (s6, pexp, mean (s4)

One-simple Kolmogorov-Smirnov test

data: $\mathrm{s} 6$

$\mathrm{D}=1, \mathrm{p}$-value $<2.2 \mathrm{e}-16$

Alternative hypothesis: two-sided

Server 5:

Fig 5: Histogram for server 5

$>$ Ks.test(s5,pexp,mean(s5)

One-sample Kolmogorov-Smirnov test

data: $\mathrm{s} 6$

$=1, \mathrm{p}$-value $<2.2 \mathrm{e}-16$

Alternative hypothesis: two-sided

Server 6:

Fig 6: Histogram for server 6

$>$ Ks.test(s5,pexp,mean(s5)

One-sample Kolmogorov-Smirnov test

data: s6

$=1$, $\mathrm{p}$-value $<2.2 \mathrm{e}-16$ 
Alternative hypothesis: two-sided

\section{Server 7:}

Fig 7: Histogram for server 7

$>$ Ks.test(s5,pexp,mean(s5)

One-sample Kolmogorov-Smirnov test

data: s6

$=1, \mathrm{p}$-value $<2.2 \mathrm{e}-16$

Alternative hypothesis: two-sided

\section{Server 8}

\section{Fig 8: Histogram for server 8}

$>$ Ks.test(s5,pexp,mean(s5)

One-sample Kolmogorov-Smirnov test

data: s6

$=1, \mathrm{p}$-value $<2.2 \mathrm{e}-16$

Alternative hypothesis: two-sided

\subsubsection{Data Analysis}

Analysis of variance test was performed using R-package. The following object(s) are masked by "GlobalEnv":

Day, server

$>$ anova $=$ aov $($ server-day,data $=$ ddat $)$

$>$ summary (anova)

\begin{tabular}{|c|c|c|c|c|c|}
\hline Source of Variation & Degree of Freedom & Sum of Squares & Mean of Squares & F-value & $\operatorname{Pr}(>\mathrm{F})$ \\
\hline Day & 7 & 13 & 1.795 & 0.188 & 0.988 \\
\hline Residuals & 381 & 3647 & 9.571 & & \\
\hline
\end{tabular}

\subsubsection{The Maximum Likelihood Ratio Test}

The test was performed using R-statistical Package

$>\mathrm{vp}$

\section{[1] 0.01630498}

$$
\text { d. } f: 8, \alpha=0.05=1.34
$$

\section{Result}

The analysis shows an important result which interprets as follows: The number of customers arrived at that time was greater than the number of the cashiers. The probability of queuing on arrival in First Bank was 0.089 and Guaranty Trust Bank was 0.00035 . These are weak probability but it is still possible for customer to wait before receiving services. The average number of customers waiting to be served in First Bank was one 
customer per minute while Guaranty Trust was one customer per minute which means at time there will be no customer in the queue.

Average time spent in the system in First Bank was 24.41 minutes and average time spent in the queue was 1.03 minutes which means that a customer spent at least 23.38 minutes in the queue.

Guaranty Trust Bank, average time spent in the system was 11.52 minutes which is shorter than that of first bank. If the time is extended to two hours in a day First Bank has 128 customers and Guaranty Trust Bank will have 11,085 customers to be attended to.

Based on the descriptive statistics and non-parametric test, the histogram and Kolmogorov-Smirnov test shows that service time does not follow exponential distribution. With the adoption of central limit theorem and the descriptive statistics (histogram) we assume that the service time is normally distributed.

The result of the Analysis of Variance (ANOVA) and maximum likelihood ratio do not reject the null hypothesis.

The assumption of service time always follows exponential distribution. It is a different case in this paper. This is not strange because individual patient comes to the hospital with different types of ailments. We cannot expect the patient diagnosed with cancer to spend the same time with the patient diagnosed with headache. Assuming the research work was carried out in a bank where customers only withdraw or save money, it will follow exponential distribution.

The result of ANOVA and Maximum Likelihood Ratio Test shows that the mean service time of the doctors are the same since the null hypothesis is not rejected. This is because there is no permanent service point for a particular doctor. Doctors are assigned to service point at random mainly because doctors are always on shift.

\section{Acknowledgements}

Our appreciation goes to my able mentor, Professor E. T. Jolayemi, of the Department of Statistics, University of Ilorin, Nigeria, who offered useful advice and suggestion during the period of statistical experiment and research. He also made correction of all mistakes.

\section{References}

[1] Artalejo J. A. and Gomez-Corral A. A state of independent Markov modulated mechanism for generating event and stochastic model, 2010.

[2] Neuts M. F. The analysis of retrial queues, $2^{\text {nd }}$ Edition Dover Publication, 1999.

[3] Ahn S., Badescu A. L. and Ramaswami V. Time dependent analysis of finite buffer fluid flows and risk model with dwident barrier, 2007.

[4] Alfa A. S. and Neut M. F. An improved distance estimation method, 1995.

[5] Allen J. R. L. Journal of Quaternary Sciences, 2003, 23(3).

[6] Asmussen S. and Koole. Journal of Applied Probability, 1993.

[7] Breur L. and Baun D. An introduction to queuing theory matrix-analytic method. Journal of Applied Probability.

[8] Dubin A. N., Nishimura S. Journal of Applied Mathematics and Stochastic Analysis, 1999, V. 12H4, $393-415,7$.

[9] Lambert J. Van Houdt B. and Blondia C. Point process with finite probabilities, 2006.

[10] Meier-Hellstern K. S. and Neuts M. F. Lume Final Program and Abstract, 1990.

[11] Halfin, S and W. Heavy-Traffic limits for queue with many exponential serves, Operational Research, 1981, 29(3)567-588.

[12] Aamatu and Ariyo (1983): An appraisal of cost queuing in Nigeria Banking Sector. 
[13] Oladapo J.O 1998: International Institution to parallel Processing.

[14] Green and Kolesar (1991): Staffing a service system with Appointment Based on Customer Awards. Journal of Operational Research Society doi 10/507/Jor 2013

[15] Beal E, M.L (1995): On minimizing a convex function subject to linear me qualities journal of the Royal statistical society.

[16] Ashly (2002): An appraisal of Cost Queuing in Nigeria. University of Iorin Publication.

\section{Authors' Profiles}

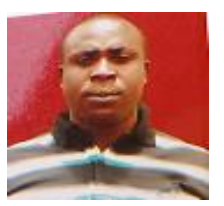

David O. Ikotun was born on the $25^{\text {th }}$ of July 1977 . He obtained higher national diploma in statistics at Federal Polytechnic, Ede in 2002. He also has post graduate diploma in statistics, 2010 at Federal University of Technology, Akure.

He obtained master in statistics from the University of Ilorin. He is currently a lecturer in the department of mathematics and statistics of Interlink Polytechnic, Ijebu Jesa, Nigeria.

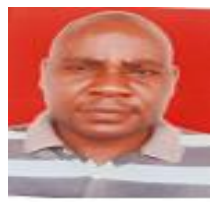

Justus A. Ademuyiwa was born on $21^{\text {st }}$ of November, 1977. He has higher national diploma, 2001 in statistics at Federal Polytechnic, Ado Ekiti.

He has post graduate diploma in statistics at Federal University of Technology, Akure and master in statistics at University of Ilorin, Nigeria. He is currently the head of department of statistics, Federal Polytechnic, Ile-Oluji, Nigeria.

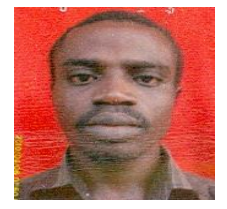

Alaba T. Owoseni, as a Nigerian in the south-west part of the country, had bachelor of technology in computer engineering from Ladoke Akintola University of Technology, Ogbomoso, Nigeria in 2009 with master of technology in computer science from Federal University of Technology Akure, Nigeria in 2015. Currently, he is preparing to commence his doctor of philosophy in computer science.

\section{APPENDIX}

Day 1

\begin{tabular}{|l|l|l|l|l|l|l|l|l|}
\hline S/N & Server1 & Server2 & Server3 & Server4 & Server5 & Server6 & Server7 & Server8 \\
\hline 1 & 17 & 13 & 14 & 15 & 19 & 14 & 13 & 12 \\
\hline 2 & 18 & 15 & 11 & 14 & 11 & 12 & 11 & 16 \\
\hline 3 & 15 & 11 & 11 & 15 & 14 & 5 & 14 & 24 \\
\hline 4 & 10 & 7 & 14 & 13 & 14 & 15 & 14 & 14 \\
\hline 5 & 13 & 13 & 14 & 18 & 16 & 16 & 12 & 15 \\
\hline 6 & 12 & 17 & 16 & 15 & 15 & 15 & 14 & 18 \\
\hline 7 & 12 & 18 & 12 & 7 & 15 & 16 & 16 & 15 \\
\hline 8 & 13 & 13 & 12 & 18 & & 12 & 12 & \\
\hline 9 & & 12 & 12 & & & 12 & 12 & \\
\hline
\end{tabular}


Day 2

\begin{tabular}{|l|l|l|l|l|l|l|l|l|}
\hline S/N & Server1 & Server2 & Server3 & Server4 & Server5 & Server6 & Server7 & Server8 \\
\hline 1 & 11 & 4 & 15 & 15 & 11 & 15 & 20 & 11 \\
\hline 2 & 11 & 9 & 11 & 9 & 12 & 12 & 11 & 2 \\
\hline 3 & 13 & 11 & 11 & 11 & 12 & 11 & 11 & 9 \\
\hline 4 & 16 & 11 & 12 & 15 & 2 & 11 & 10 & 9 \\
\hline 5 & 14 & 11 & 11 & 12 & 10 & 11 & 11 & 9 \\
\hline 6 & 14 & 11 & 11 & 13 & 13 & 11 & 12 & 12 \\
\hline 7 & 12 & 18 & 11 & 13 & 12 & 11 & 10 & ${ }^{5} 11$ \\
\hline 8 & 11 & 9 & 11 & 11 & 9 & 11 & 11 & 11 \\
\hline 9 & 11 & 11 & 10 & 8 & 11 & 10 & 10 & 12 \\
\hline 10 & 2 & 10 & & 8 & 15 & 12 & 7 & 14 \\
\hline 11 & & 8 & & & & & & \\
\hline 12 & & 8 & & & & & & \\
\hline
\end{tabular}

Day 3

\begin{tabular}{|l|l|l|l|l|l|l|l|l|}
\hline S/N & Server1 & Server2 & Server3 & Server4 & Server5 & Server6 & Server7 & Server8 \\
\hline 1 & 13 & 13 & 11 & 15 & 2 & 10 & 2 & 10 \\
\hline 2 & 12 & 10 & 11 & 14 & 13 & 13 & 13 & 12 \\
\hline 3 & 11 & 9 & 8 & 8 & 14 & 12 & 15 & 13 \\
\hline 4 & 9 & 9 & 11 & 8 & 12 & 11 & 8 & 12 \\
\hline 5 & 11 & 9 & 11 & 11 & 12 & 9 & 11 & 12 \\
\hline 6 & 10 & 12 & 13 & 11 & 15 & 12 & 11 & 12 \\
\hline 7 & 9 & 13 & 13 & 12 & 13 & 11 & 11 & 13 \\
\hline 8 & 11 & 11 & 11 & 8 & 11 & 11 & 11 & 10 \\
\hline 9 & 9 & 11 & 8 & 8 & 9 & 11 & 12 & 11 \\
\hline 10 & 9 & 7 & 8 & 10 & 10 & 15 & 12 & \\
\hline 11 & 6 & 6 & & & & & & \\
\hline
\end{tabular}

Day 4

\begin{tabular}{|l|l|l|l|l|l|l|l|l|}
\hline S/N & Server1 & Server2 & Server3 & Server4 & Server5 & Server6 & Server7 & Server8 \\
\hline 1 & 12 & 11 & 12 & 10 & 13 & 12 & 15 & 13 \\
\hline 2 & 8 & 14 & 7 & 9 & 9 & 9 & 11 & 9 \\
\hline 3 & 9 & 10 & 2 & 11 & 8 & 9 & 9 & 9 \\
\hline 4 & 9 & 2 & 8 & 2 & 9 & 9 & 11 & 9 \\
\hline 5 & 9 & 8 & 12 & 8 & 9 & 9 & 11 & 9 \\
\hline 6 & 9 & 12 & 11 & 12 & 9 & 12 & 11 & 10 \\
\hline 7 & 10 & 8 & 9 & 13 & 14 & 11 & 12 & 11 \\
\hline 8 & 9 & 12 & 11 & 15 & 12 & 11 & 12 & 13 \\
\hline 9 & 11 & 9 & 12 & 14 & 8 & 11 & 11 & 9 \\
\hline 10 & 9 & 9 & 11 & 12 & 8 & 12 & 7 & 9 \\
\hline 11 & 9 & 9 & 9 & 4 & 9 & 9 & & 9 \\
\hline 12 & 6 & 11 & 6 & & & 4 & & \\
\hline
\end{tabular}


Day 5

\begin{tabular}{|l|l|l|l|l|l|l|l|l|}
\hline S/N & Server1 & Server2 & Server3 & Server4 & Server5 & Server6 & Server7 & Server8 \\
\hline 1 & 15 & 13 & 14 & 16 & 14 & 15 & 14 & 13 \\
\hline 2 & 15 & 18 & 13 & 13 & 12 & 11 & 13 & 4 \\
\hline 3 & 6 & 18 & 14 & 16 & 16 & 15 & 11 & 13 \\
\hline 4 & 14 & 14 & 15 & 9 & 12 & 15 & 12 & 13 \\
\hline 5 & 16 & 14 & 14 & 15 & 14 & 12 & 15 & 12 \\
\hline 6 & 19 & 13 & 14 & 15 & 14 & 13 & 12 & 14 \\
\hline 7 & 11 & 20 & 12 & 11 & 12 & 15 & 14 & 13 \\
\hline 8 & 11 & & 11 & 10 & 10 & 12 & 16 & 9 \\
\hline 9 & & & 10 & 10 & 10 & 8 & 10 & 9 \\
\hline
\end{tabular}

How to cite this paper: David O. Ikotun, Alaba T. Owoseni, Justus A. Ademuyiwa,"Service Time Management of Doctor's Consultation Using Parallel Service T me in Wesley Guild Hospital, Ilesa, Osun State, Nigeria", International Journal of Mathematical Sciences and Computing(IJMSC), Vol.3, No.1, pp.49-62, 2017.DOI: 10.5815/ijmsc.2017.01.05 